\title{
OPEN Author Correction: Overcoming NADPH product inhibition improves D-sorbitol conversion to L-sorbose
}

\author{
Tae-Su Kim ${ }^{1,2}$, Hui Gao ${ }^{1}$, Jinglin $\mathrm{Li}^{1}$, Vipin C. Kalia ${ }^{1}$, Karthikeyan Muthusamy ${ }^{3}$, \\ Jae Kyung Sohng ${ }^{2}$, In-Won Kim ${ }^{1}$ \& Jung-Kul Lee ${ }^{1}$
}

Correction to: Scientific Reports https://doi.org/10.1038/s41598-018-37401-0, published online 28 January 2019

The original version of this Article contained a typographical error in the name of author Hui Gao, which was incorrectly given as Gao Hui. This has now been corrected in the PDF and HTML versions of the Article, and in the accompanying Supplementary Information file.

(c) (i) Open Access This article is licensed under a Creative Commons Attribution 4.0 International License, which permits use, sharing, adaptation, distribution and reproduction in any medium or format, as long as you give appropriate credit to the original author(s) and the source, provide a link to the Creative Commons license, and indicate if changes were made. The images or other third party material in this article are included in the article's Creative Commons license, unless indicated otherwise in a credit line to the material. If material is not included in the article's Creative Commons license and your intended use is not permitted by statutory regulation or exceeds the permitted use, you will need to obtain permission directly from the copyright holder. To view a copy of this license, visit http://creativecommons.org/licenses/by/4.0/.

(C) The Author(s) 2019

\footnotetext{
${ }^{1}$ Department of Chemical Engineering, Konkuk University, 1 Hwayang-Dong, Gwangjin-Gu, Seoul, 05029, Republic of Korea. ${ }^{2}$ Department of Life Science and Biochemical Engineering, SunMoon University, 70 Sunmoon-ro 221, Tangjeong-myeon, Asan-si, Chungnam, 31460, Republic of Korea. ${ }^{3}$ Department of Bioinformatics, Alagappa Uiversity, Karaikudi, Tamil Nadu, India. Tae-Su Kim and Hui Gao contributed equally. Correspondence and requests for materials should be addressed to I.-W.K. (email: inwon@konkuk.ac.kr) or J.-K.L. (email: jkrhee@konkuk.ac.kr)
} 